\title{
Preparing the scientific basis for an all metal ITER
}

\author{
R. Neu, ASDEX Upgrade Team $\ddagger$, EU PWI Taskforce and JET EFDA \\ Contributors $\S$ \\ JET-EFDA, Culham Science Centre, Abingdon, OX14 3DB, UK \\ Max Planck Institut für Plasmaphysik, EURATOM Association, 85748 Garching, Germany
}

\begin{abstract}
The use of beryllium, carbon and tungsten as plasma-facing materials (PFMs) in ITER calls for dedicated investigations on their behaviour under the expected particle and power loads and neutron irradiation. Their simultaneous use implies the formation of mixed materials during plasma operation, which can have significantly different properties compared to the initial materials concerning thermo-mechanical behaviour and $\mathrm{T}$ retention. This contribution presents the latest results on these issues mainly achieved under the umbrella of the European taskforce on Plasma Wall Interaction. While laboratory results provide the basis for the understanding of the basic properties and the behaviour of PFMs, experiments in fusion devices are indispensable in order to test their integral performance, incorporating also the internal feedback on the plasma properties. For this reason ASDEX Upgrade has been converted to a full $\mathrm{W}$ device, while JET is beginning operation with its ITER-like wall consisting of a Be main chamber plasma-facing components and a $\mathrm{W}$ divertor. In parallel, dedicated $\mathrm{W}$ experiments are performed in several devices in order to investigate specific uncertainties such as the characteristics of melt layer movement in the presence of a strong magnetic field. Based on the results on ASDEX Upgrade, which reveal a narrower operational space as compared to the operation with graphite plasma facing components but also provide tools for a successful operation with tungsten, the experiments at JET will provide a unique opportunity to address specific issues related to the parallel use of Be and W as PFMs with plasma parameters closest to those of ITER. Amongst these are the anticipated but still to be demonstrated reduction in hydrogen retention compared to a carbon device, the test of conditioning procedures, mixed materials effects, erosion and transport, the effect of ELMs and ELM mitigation methods as well as the behaviour of melt layers and their influence on plasma operation under steady state and transient heat loads.
\end{abstract}

PACS numbers: 52.40.Hf, 52.25.Vy, 28.52.Fa, 52.55.Rk, 52.55.Fa

¥ See A. Kallenbach et al., Proc. of the 23rd IAEA Fusion Energy Conference 2010, Daejeon, Korea

$\S$ See Appendix of F. Romanelli et al., Proc. of the 23rd IAEA Fusion Energy Conference 2010, Daejeon, Korea 


\section{Introduction}

Plasma wall interaction (PWI) research and development has become a priority for the international fusion community now that work is focusing on next step devices such as ITER or DEMO because of the huge extrapolation necessary in terms of particle fluence and transient power loads. In response, several European devices have implemented intensive research programs dealing with issues on PWI such as the $\mathrm{W}$ programme in ASDEX Upgrade [1] or the ITER-like wall project at JET [2]. In addition, EFDA (European Fusion Development Agreement) has created a Task Force on PWI already in 2002 (see for example [3]) with the aim of concentrating European research on the most urgent problems in the field of PWI and of proposing scientific and technological concepts to overcome these problems.

Currently, ITER has adopted beryllium (Be) as first wall and tungsten (W) as divertor armour material, in order to minimize the co-deposition of tritium with carbon (C) [4]. Nevertheless it is foreseen to use carbon fibre composite (CFC) at the divertor strikepoints in the initial phase in order to reduce technical risk during the learning curve of the commissioning process. The use of these three materials implies the formation of mixed materials during plasma operation, which can have significantly different properties, in particular thermo-mechanical behaviour and hydrogen retention, compared to the pristine materials. Although C-erosion will not play a role for the co-deposition of $\mathrm{T}$ after removal of the CFC components, it still may be abundant enough to lead to measurable T retention. Moreover, laboratory data on T co-deposition with Be has sufficient range that T-retention could still be significant in ITER. Therefore techniques for T removal applicable to the ITER materials mix have to be investigated.

A major drawback of metals as plasma-facing materials (PFMs) is the appearance of melting under transient heat loads and the absence of 'plasma shaping', the change of the component's surface by the plasma providing the least PWI. There are several areas which benefit from investigations in dedicated (laboratory) devices. Amongst these are the behaviour of materials under repetitive power and particle loads as well as the behaviour of neutron irradiated plasma facing components (PFCs) and PFMs. To some extent electron beam devices may serve as an important tool in a relatively fast qualification of material grades (alloys) on complete components [5]. The power deposition of electrons differs considerably from those of ions and the effect of particle penetration and diffusion on the material properties has to be taken into account. Therefore ion beams and, to a greater extent, linear plasma devices [6] with sufficiently high particle and energy flux achieve the closest possible simulation of 'real' fusion devices. What is missing in such experiments, however, is the shallow angle of incidence of the particles and the strong magnetic field ambient in fusion devices having an impact on the microscopic motion of the eroded particles (gyro motion, prompt redeposition), the macroscopic behaviour of melt layers (MHD effects) and curvature related particle drifts which are present in a toroidal machine. A device coming currently closest to the properties of a fusion divertor plasma is PILOT PSI [7]. It allows not only plasma densities above $10^{20} \mathrm{~m}^{-3}$ and electron temperatures in the range $1-5 \mathrm{eV}$, but it is also operated at a magnetic field of up to $1.6 \mathrm{~T}$ and only recently it has been equipped with a capacitor bank to superimpose power transients of up to $1 \mathrm{MJ} \mathrm{m}^{-2}$ of duration about $1 \mathrm{~ms}$ [8] - values very close to that expected 
in ITER during mitigated ELMs. Another important linear device is PISCES-B operated at UCSD ([9] and references therein) partially supported by EFDA, which allows to investigate PWI with beryllium targets.

While laboratory results provide the basis for an understanding of the basic properties and the behaviour of PFMs under expected loads, experiments in fusion devices are indispensable in order to gain an integral view on the behaviour of the PFMs and their role for the plasma performance, incorporating also the internal feedback of the PFC behaviour on the plasma properties. For this reason, ASDEX Upgrade has been converted to a full $\mathrm{W}$ device [10], while JET is beginning to operate with its ITER-like wall consisting of a Be main chamber plasma-facing components and a $\mathrm{W}$ divertor [11]. In parallel, dedicated local $\mathrm{W}$ experiments are being performed in TEXTOR in order to investigate specific questions such as the nature of melt layer motion in the presence of a strong magnetic fields [12]. Based on the results from ASDEX Upgrade, which reveal a narrower operational space as compared with graphite plasma facing components (mainly in the accessible density range) but also provide tools for a successful operation with tungsten (see Sec. 3.1), the experiments at JET will provide the unique opportunity to address specific issues related to the parallel use of Be and W as PFMs with plasma parameters closest to those of ITER. Amongst these are the anticipated but not certain reduction in fuel retention compared to a carbon device, the test of ITER relevant conditioning procedures, mixed materials effects, $\mathrm{W}$ erosion and transport in ITER relevant scenarios (baseline and advanced), the effect of ELMs and ELM mitigation methods as well as the behaviour of melt layers under steady state and transient heat loads.

Due to space restriction, details on the design parameters and optimization criteria for the ITER PFCs cannot be reproduced here. For recent reviews on the underlying boundary conditions the reader may refer to [13, 14] and for the resulting solutions to $[15,4,16]$. In [17] some of the main hazards anticipated for PWI in ITER are discussed. Fig. 1 summarizes the result of these investigations into achievable discharges operating within the limits imposed by erosion, dust generation and tritium inventory for four material options, assuming steady state loading conditions and neglecting major transient events. For the all metal solutions using $\mathrm{Be} / \mathrm{W}$ or only $\mathrm{W}$ as PFM the predicted number of allowed discharges is largest (indicated by the 'inner' polygon). Although new results became available during the last two years the overall picture is still valid, showing that the Be erosion and/or T co-deposition with Be are the most limiting issues in the foreseen Be/W solution for ITER. It has to be noted, however, that the other issues listed above (as for example behaviour under transients, influence on plasma performance) have to be taken into account in the decision for a specific combination of PFMs. There are several reviews available in the recent literature (see for example [18, 19] and references therein) dealing with the use of $\mathrm{W}$ in fusion devices. Moreover, there is also a recent paper on the combination of Be and W as PFMs in ITER [20] concentrating mostly on code predictions. This paper will put more emphasis on the experimental aspects with a specific focus on the upcoming experiments in the JET ITER-like wall campaigns.

The next section will concentrate on the latest results on PWI phenomena relating to the PFMs beryllium and tungsten. Since tungsten is able to strongly influence plasma performance, Sec. 3 highlights methods to keep the $\mathrm{W}$ content low and the current attempts 


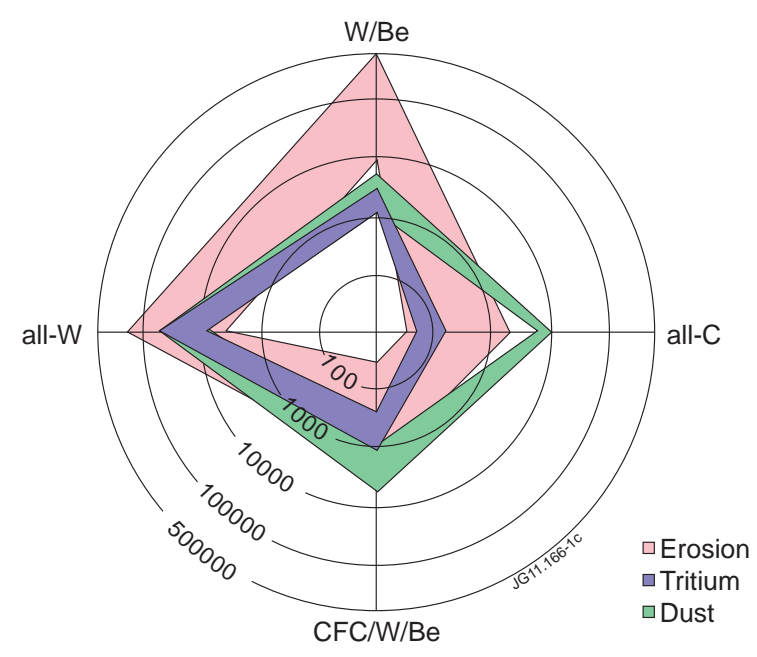

Figure 1. Extrapolated number of discharges (duration 400 s) allowed before reaching the safety limits due to erosion, dust generation and tritium inventory for four material options in ITER under steady state loading conditions [17].

for developing an integrated scenario. Sec. 4 is devoted to the JET ITER-like Wall (ILW) project, its implementation, the physics preparation and the envisaged programme designed to answer the most urgent questions in support of ITER. Sec. 5 will provide a short summary and finally Sec. 6 will conclude the paper.

\section{Recent results on beryllium and tungsten plasma wall interaction}

\subsection{Erosion}

Physical sputtering results from elastic energy transfer from incident particles to target atoms. Surface atoms can be ejected, if enough energy is transferred to overcome the surface binding energy [21]. At low ion energies, where the transferred energy to surface atoms is comparable with the surface binding energy, the sputtering yield decreases strongly and becomes zero below a threshold energy. The threshold energy for the onset of sputtering from light projectiles on a substrate consisting of heavier species can be determined from momentum and energy conservation in an elastic collision.

Whereas there is almost no threshold for the chemical erosion of carbon $(\approx 2 \mathrm{eV})$, which leads to rather high yields at very low plasma temperatures [22], the threshold for physical sputtering of beryllium is below $10 \mathrm{eV}$ for all $\mathrm{H}$ isotopes due to the low atomic mass of beryllium leading to efficient momentum transfer with plasma particles. Although in general TRIM.SP [23] calculations satisfactorily reproduce experimental results on sputter yields, there are large deviations in the case of Be. Ion beam experiments point to maximum sputter yields of $8 \%$ [24], whereas measurement in PISCES-B [25], which were confirmed only recently under controlled surface conditions [26], reveal maximum yields below $1 \%$. The situation is even more complicated under typical conditions existent in a fusion device. In 
JET the measured yields reach up to several tens of percent $[27,28]$ under high plasma temperatures limiter conditions $\left(T_{e} \approx 40 \mathrm{eV}\right)$ but also values lower than $1 \%$ in the divertor under the presence of additional carbon. The maximum yield calculated by TRIM is 2 - 3 $\%$ and the reasons for this huge discrepancies are not completely resolved yet, but effects of the incident angle, the surface morphology and temperature, plasma impurities and Be selfsputtering are under discussion. Since the effective Be sputtering rate will be very important and probably limiting for the lifetime of ITER PFCs, especially at the upper low field side part of the first wall $[29,30]$, JET will perform specific experiments to try to resolve the uncertainty in the Be erosion under tokamak conditions.

For tungsten the sputtering thresholds for $\mathrm{H}, \mathrm{D}$ and $\mathrm{T}$ on $\mathrm{W}$ are $\approx 450 \mathrm{eV}, 210 \mathrm{eV}$ and 140 $\mathrm{eV}$, respectively [31] and therefore the $\mathrm{W}$ erosion by background ions is almost negligible in a high recycling divertor plasma and the observed erosion is mainly due to intrinsic impurity ions due to their higher mass and electrical charge. W sputtering in ASDEX Upgrade could be explained in a wide range of divertor plasma temperatures by assuming an admixture of 1-2 \% low-Z impurities (C, O) in the charge state of $Z=4$ [32].

An obvious question is whether impurity seeding leads to a higher $\mathrm{W}$ source due to more efficient sputtering by heavier species impinging at a potentially higher charge state resulting in higher energies. Experiments with $\mathrm{Ne}$ and $\mathrm{N}_{2}$ seeding in ASDEX Upgrade [32, 33, 34] showed that at least in between ELMs (see below) a reduction of the $\mathrm{W}$ influx could be achieved due to the strong cooling of the divertor plasma which overcompensates the higher sputtering yield of the impurity ions. In general, similar erosion yields (using the yields from [21]) are expected for ITER relevant divertor parameters using estimated concentrations and charge states relevant to ITER as indicated in Fig. 2. The sputter yields do not take surface roughness into account and the plasma impurity concentration is assumed to vary with $1 / \mathrm{Z}$, since the main plasma $\Delta P_{\text {rad }} / \Delta Z_{\text {eff }}$ rises with the impurity charge [35].

When comparing the $\mathrm{W}$ gross erosion, typically measured by spectroscopic means, with the net erosion from probe measurements, a difference by a factor of up to 10 is found under low temperature high density conditions [32]. This is attributed to 'prompt re-deposition' as it was already observed in $\mathrm{W}$ marker experiments [37]: For high-Z materials the gyroradius in the external field can be larger than the ionisation length, which can lead to deposition of the eroded particle directly after its erosion. More recent investigations show about a factor of three reduction for campaign integrated erosion in the divertor of ASDEX Upgrade [38] compared to the gross erosion measured by spectroscopic means, which may be attributed to the fact that the divertor plasma is not always dense enough for a high prompt re-deposition fraction. Recently the prompt re-deposition was measured to be $>50 \%$ by insitu by spectroscopy - comparing WI and WII fluxes [39]. Details of this process are still under investigation, because it could diminish further the low sputtering yield under ITER high density, low temperature conditions.

Besides the erosion by a thermal steady state plasma, erosion by transients can play an important role, because they lead to increased yields or even to melting of the surfaces (see next subsection) by the rapid energy deposition. During edge localized modes (ELMs), not only the particle flux is increased, but also the particles' energy, as they originate from the hot 


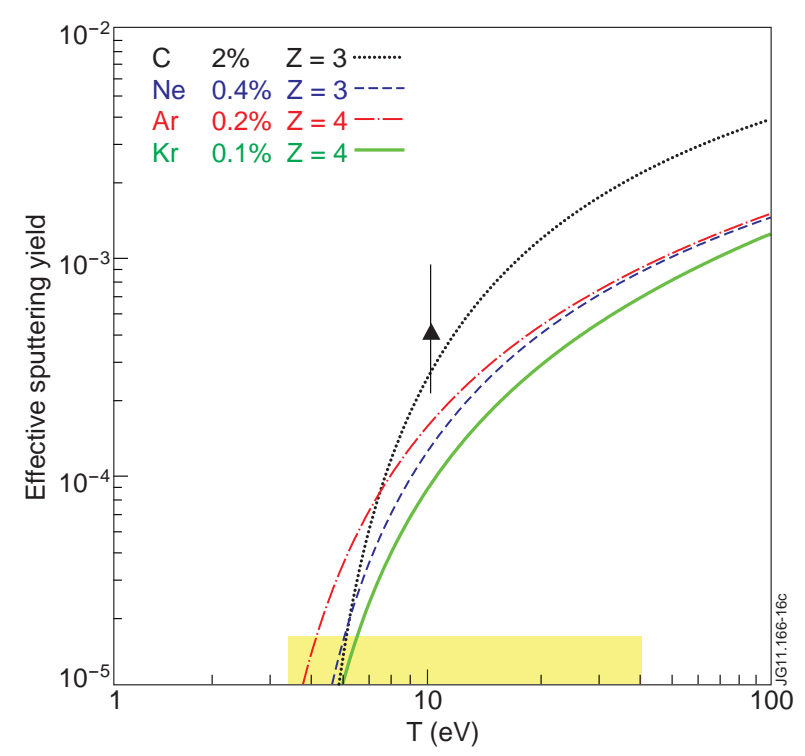

Figure 2. Effective tungsten sputtering yields for different impurity species versus plasma temperature, assuming $E_{\text {impact }}=3 Z T+2 T$. The yields are calculated by multiplying the sputter yield of an impurity species with its (assumed) concentration and the charge state given in the insert. The triangle indicates the effective erosion yield measured in $A U G$ at $T_{e} \approx 10 \mathrm{eV}$ resulting from intrinsic impurities and the bar gives the typical variation observed for different discharges [36].

edge region ('pedestal') of the main plasma. Measurements in ASDEX Upgrade using high spatial and temporal resolution reveal, that under high density conditions, the $\mathrm{W}$ sputtering in between ELMs is strongly suppressed and that the sputtering during ELMs contributes up to $70 \%$ (main chamber, [40]) or $90 \%$ (divertor, [38]) of the total $\mathrm{W}$ erosion.

Another important process for increasing the sputter source of high-Z PFCs is the acceleration of plasma and impurity ions in the rectified sheath due to ion cyclotron resonance heating (ICRH). This is reported from ASDEX Upgrade as well as from Alcator C-Mod, which is a high field tokamak with bulk molybdenum PFCs and a toroidal ring of bulk W tiles at the outer divertor strikepoint region, where the $\mathrm{W}$ fluxes and Mo fluxes, respectively, increase by about a factor of ten during the operation of ICRH $[41,42,36,38]$. In both experiments it is also found that the divertor impurity source is almost unchanged and, although being still larger than the limiter source, the impurity concentration in the main plasma is clearly dominated by the limiter source. This hints at a good divertor retention of Mo and $\mathrm{W}$, respectively, which has also been determined quantitatively by trace $\mathrm{W}$ injections in ASDEX Upgrade [43]. The divertor retention describes the capability of the divertor to suppress the impurity influx towards the main plasma. It can be defined by the ratio of the penetration probabilities of impurities into the confined plasma released in the main chamber versus that of impurities released in the divertor.

As an example, Figure 3 shows the temporal evolution of some plasma parameters for an ASDEX Upgrade discharge with different heating methods [10]. The W-influx is deduced from the W I line at $400.9 \mathrm{~nm}$ as described in [38]. The $\mathrm{W}$ concentration is deduced from 


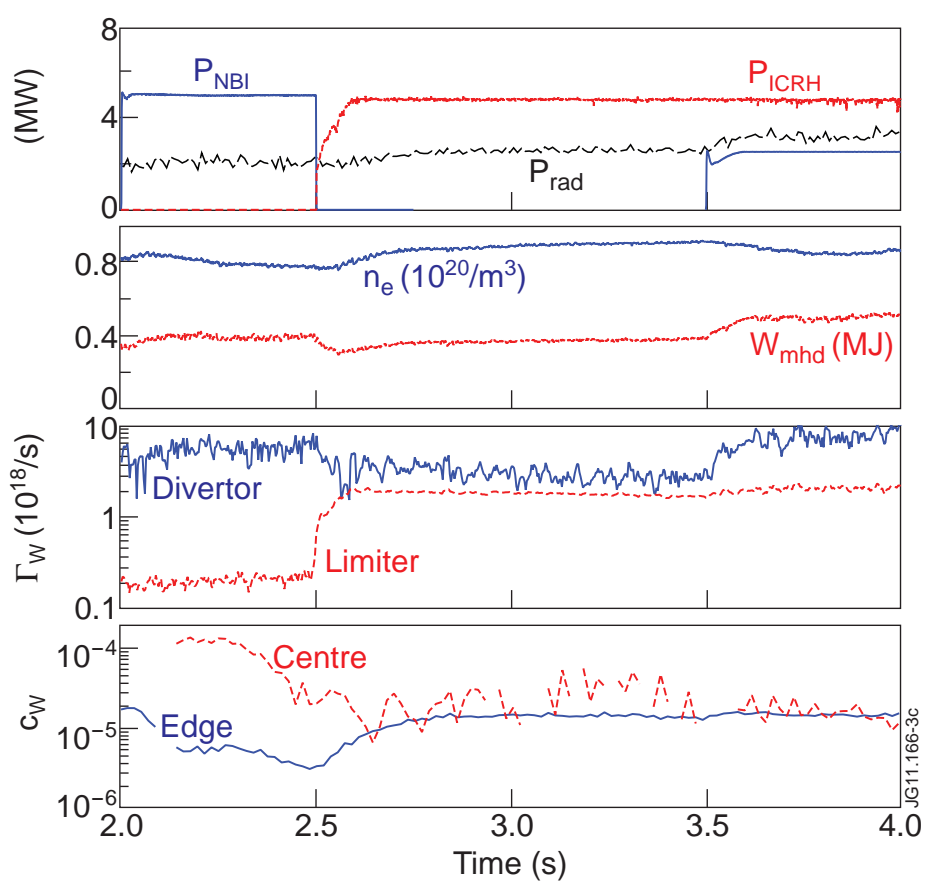

Figure 3. $\mathrm{W}$ influx and $\mathrm{W}$ concentration in ASDEX Upgrade during discharge \#23476. The two top graphs present the heating power $\left(P_{N B I}, P_{I C R H}\right)$ and total radiation $\left(P_{r a d}\right)$ as well as the line averaged density $\left(n_{e}\right)$ and the stored energy $\left(W_{m h d}\right)$ of the plasma. The third graph highlights the $\mathrm{W}$ influx $\left(\Gamma_{W}\right)$ from the limiters and the divertor and the bottom insert shows the deduced $\mathrm{W}$ concentration $\left(c_{W}\right)$ at the plasma edge and the centre.

the quasi-continuum emission at $5 \mathrm{~nm}$ and the spectral line at $0.794 \mathrm{~nm}$ emitted from Nilike $\mathrm{W}^{46+}$ [44]. The first one gives the $\mathrm{W}$ concentration close to the plasma edge (around $\left.T_{e} \approx 1 \mathrm{keV}\right)$, whereas the latter one represents the central concentration $\left(T_{e} \approx 3 \mathrm{keV}\right)$ in typical ASDEX Upgrade discharges. During the first phase (until $t=2.5 \mathrm{~s}$ ) the plasma is heated by neutral beam injection (NBI) only. During this phase the $\mathrm{W}$ source at the limiter in the main chamber is more than a factor of ten smaller than the divertor $\mathrm{W}$ source. At the same time the $\mathrm{W}$ concentration is strongly peaked, as can be seen from the ratio of the central to edge $\mathrm{W}$ concentration, which is about 20 . This strong peaking is usually explained by neoclassical inward drifts (see Sec. 3.1), which can be dominant in the absence of large turbulent transport or macroscopic instabilities as sawteeth [45]. At $t=2.5 \mathrm{~s}$ the NBI is switched off and at the same time the ion cyclotron resonance heating is switched on. Immediately, the limiter source increases by a factor of 10 . At the same time the central concentration decreases leading to a flat $\mathrm{W}$ density profile. This behaviour is attributed to an increase in turbulent transport which is described in more detail in Sec. 3.1. In the third phase of the discharge from $t=3.5 \mathrm{~s}$ on, a part of the NBI is switched on again, resulting in an increased W source in the divertor, which is not reflected in the main chamber concentrations at all.

Recent experiments with rearranged antenna pairs which allow a discrete operation of neighboring antennas in a wide range of plasma parameters showed that the connection length of flux tubes starting at limiters can undergo a step-like change which correlates to dramatic changes of the $\mathrm{W}$ sputtering patterns measured spectroscopically. This indicates that the local 
magnetic geometry is at least as important for the $\mathrm{W}$ sputtering as the distribution of RF nearfields at the antenna. The sputtering is also likely to be influenced by $E \times B$ density convection in front of the antenna, which is implied from the experiments comparing discharges with normal vs. reversed toroidal field [46].

\subsection{Hydrogen Retention}

As stated in the introduction, one of the major goals of replacing carbon based PFCs to metallic PFCs is the reduction of the hydrogen retention. The retained hydrogen in plasma exposed Be surface saturates at rather low levels $\approx 10^{21} \mathrm{~m}^{-2}$, thereby the in-vessel tritium accumulation will be dominated by co-deposition, hence strongly depending on erosion rates of Be (see Sec.2.1). Fig. 4 shows the measured fraction of co-deposited deuterium with $\mathrm{C}$, Be and $\mathrm{W}$ ([17] and references therein) as a function of deposition temperature. As it can easily be seen, the $\mathrm{D}$-fraction co-deposited with $\mathrm{Be}$ is only about a factor of 5 lower than that of $\mathrm{C}$, which implies significant $\mathrm{H}$ retention for large Be erosion rates. Mixtures of $\mathrm{Be}$ and $\mathrm{C}$ or $\mathrm{Be}$, $\mathrm{C}$ and $\mathrm{O}$ are even closer to $\mathrm{C}$ in terms of the co-deposited deuterium fraction as it is indicated in the figure (see also for example [47]).

In view of this potentially large $\mathrm{H}$ retention, the release from pure $\mathrm{Be}$ and mixed $\mathrm{Be}-\mathrm{C}$ or $\mathrm{Be}-\mathrm{W}$ layers was investigated in [48]. In pure $\mathrm{Be}, \mathrm{D}$ is predominantly released around 420 $470 \mathrm{~K}$ within a relatively sharp desorption peak. Mixing of tungsten (W) or carbon (C) in Be changes the $\mathrm{D}$ release behaviour resulting in less efficient $\mathrm{D}$ removal by baking. Especially, the admixture of $\mathrm{C}$ in Be makes it difficult to remove the retained $\mathrm{D}$ by baking even at 623 $\mathrm{K}$. As a consequence, it is expected that the baking procedure at $623 \mathrm{~K}$ in ITER will be efficient only for tritium removal from the first wall and Be-rich deposited layers formed at low temperature areas $(<423 \mathrm{~K})$, while its efficiency is strongly reduced for C-rich codeposited layers or at PFCs where Be is deposited above $623 \mathrm{~K}$ during the operation.

For pure tungsten, a very recent review [49] mostly based on laboratory experiments $[50,51,52]$ has shown, that the hydrogen retention will not cause a challenge in ITER even when taking into account effects of radiation damage [53,54]. It has to be stated however that the possible influence of increased $\mathrm{H}$ diffusion along grain boundaries as modelled in [55] is not yet taken into account.

During the transition of ASDEX Upgrade (AUG) from graphite to tungsten, a reduction of the deuterium retention by almost a factor of ten has been observed. This is due to the strong suppression of D co-deposition with carbon as investigated by post-mortem surface analysis [56, 57]. Additionally, dynamic gas balance measurements, where the retention is derived from the difference of the puffed and the pumped amount of gas [58] show a similar reduction. It has to be stated that 'static' gas balance measurements in Alcator C-Mod, where all pumps are switched off or separated from the vacuum vessel and the retained amount is calculated from the injected gas puff and from the pressure inside the vacuum level after the discharge led to a much higher fraction of hydrogen retention $(\approx 20-50 \%)$ [59], which could be reproduced by similar measurements in ASDEX Upgrade [60]. However, at least in the case of the AUG measurements this could be interpreted as the amount of gas needed for wall 


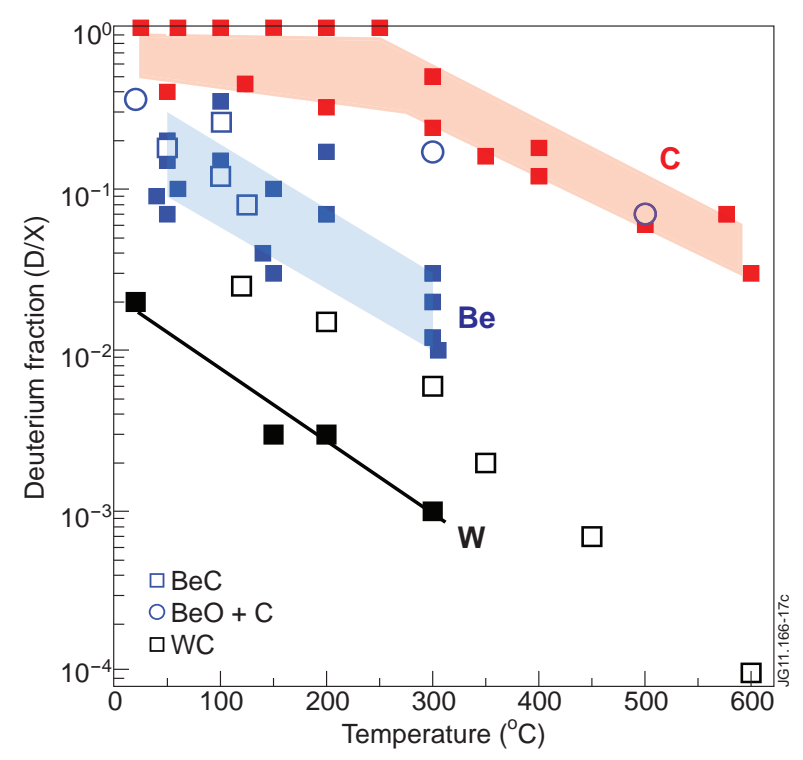

Figure 4. Measured deuterium co-deposition with carbon, beryllium and tungsten versus deposition temperature [17].

saturation.

The only conditioning and removal method besides running plasma discharges, which is accessible during normal operation are Ion Cyclotron Wall Conditioning and baking of the vessel walls and the divertor. The baking temperatures in ITER are foreseen to be $623 \mathrm{~K}$ for the divertor and $513 \mathrm{~K}$ for the main chamber wall [4]. According to [61] these temperatures would be sufficient to release the major amount of tritium from pure beryllium. However, mixtures of $\mathrm{Be} / \mathrm{W}$ and $\mathrm{Be}$ with residual $\mathrm{C}$ could require temperatures higher than $623 \mathrm{~K}$. Concerning ICWC coordinated efforts in several European devices are pursued $[62,63]$ in the framework of the EU PWI taskforce to asses the effectiveness of this method. The idea is to produce enough energetic neutral particles (mainly deuterium) to remove tritium even in remote areas via isotope exchange. It has been shown that some isotopic exchange can be achieved. But in order to be sufficient for the ITER needs it requires further optimization, because the isotope exchange is up to now only achieved by implantation of large amounts the ICWC working gas, which will be released during subsequent plasma discharges. This probably will require higher $\mathrm{T}$ injection which in consequence could cancel to some extent the effect of $\mathrm{T}$ removal.

Although exposure of PFMs in present day tokamaks is the most realistic test of their behaviour under fusion plasma conditions, there is still a big step in scaling to ITER or a reactor. In particular, the particle fluence impinging on surfaces will be much higher in reactor scale devices, because of the very low duty cycle of present day fusion devices. In order to close this gap, experiments are performed in (linear) plasma devices, allowing much larger irradiation times. Under high hydrogen fluence, low surface temperature conditions $(<600 \mathrm{~K})$ blistering of $\mathrm{W}$ can be observed (see for example [64, 65]), which could increase the hydrogen inventory and lead to increased erosion if the blister cap is removed in course of power loading [66]. Many investigations have been performed to uncover the precise conditions for the 
formation of blisters. Very recently, experiments performed in PISCES-B revealed [67] that blisters are completely suppressed and the hydrogen retention is drastically reduced, when $\approx 5 \% \mathrm{He}$ is added to the hydrogen.

In the temperature range of 1000 to $2000 \mathrm{~K}$ a nano-structure is formed at the $\mathrm{W}$ surface if exposed to He ions with energies above $20 \mathrm{eV}$ [68, 69, 70]. Its formation is observed in pure $\mathrm{He}$ plasmas as well as in mixtures of $\mathrm{He}$ and $\mathrm{H}$. The thickness of this nano-structure can reach several microns, depending on He flux and fluence. The time dependence hints at a diffusive process that is slower than the diffusion of $\mathrm{He}$ in $\mathrm{W}$ but much faster than void/bubble diffusion [69], but other formation processes as for example the coalescence of helium bubbles at the surface are also considered [70]. The impact of $\mathrm{W}$ surface nano-structure morphology on fusion reactor performance is not yet fully clear but these structures could potentially lead to a larger $\mathrm{W}$ erosion and to an increased dust production. Mostly, the growth of the $\mathrm{W}$ nanostructure was investigated under non eroding conditions. Only recently, experiments were performed increasing the energy of the impinging He above the sputtering threshold [71]. Under these eroding conditions the growth of the nano-structure is reduced and an equilibrium thickness is observed in agreement with simulations. These simulation predict a thickness of a few hundred nanometers for an erosion yield of $10^{-4}$. It has to be noted, however, that recent experiments in TEXTOR with pre-produced W nano-structures showed a complete removal of the layer even under conditions which should lead to a further growth [72].

\subsection{Arcs and Melting}

Although not a main focus of attention for quite some years, it has been found that arcs can play a significant role as an additional erosion process [73], especially if the plasma sputter-rates are rather low as in the case of tungsten. The effect of arcs was investigated post mortem in AUG [74, 75]. The arc tracks were observed at different locations, i.e. at tiles with direct plasma contact, such as divertor targets, as well as components remote from the plasma. The track orientation and pattern allow one to distinguish between arcs burning during glow discharges and during plasma operation. The arcs during plasma operation clearly dominate and are especially found at the baffle region of the inner divertor in a $10 \mathrm{~mm}$ wide region near to the leading edge of the individual tiles around the whole toroidal circumference. They cover more than $10 \%$ of this area and removed the entire tungsten coating $(3-4 \mu \mathrm{m})$. Droplets splashed from the arc track are detected at the surface close to the arc. Similar droplets are found all over the vessel $[76,77]$, pointing to the fact that arcs could significantly contribute to the dust inventory. This is especially important since this source can barely be accounted for by spectroscopic means and estimations on dust productions based on spectroscopic erosion measurements could significantly underestimate the actual value. Since it is obvious from the above stated observations that the ignition of arcs strongly depends on surface material and conditions, the specific geometry of the PFCs as well as on the plasma behaviour itself, investigations in other devices as Alcator C-Mod and JET should be performed to allow a further quantification of their contribution to the total erosion.

An even more serious erosion mechanism could be melting and subsequent melt layer losses. 
However, in all present day devices, there is not enough energy deposited neither during ELMs nor during disruptions (except melting of molybdenum in Alcator C-Mod), to cause $\mathrm{W}$ melting. In controlled melt experiments in TEXTOR, the melt-layer motion, macroscopic tungsten erosion from the melt layer as well as the changes of material properties such as grain-size and abundance of voids or bubbles were investigated [12, 78]. Test limiter samples were exposed at an impact angle of $35^{\circ}$ to power densities of $20-30 \mathrm{MWm}^{-2}$. Melt-layer motion perpendicular to the magnetic field was observed following a Lorentz-force originating from thermoelectric emission of the hot sample. The motion of melt and the changes in surface topology are in agreement with the MEMOS-3D code [79]. Due to the corrugated surface after the initiation of the melting process (the melt layer depth was $1-1.5 \mathrm{~mm}$ ), some areas were subsequently exposed to even higher heat fluxes of up to $45 \mathrm{MWm}^{-2}$ due to the degradation in the surface geometry. Therefore, the temperature reached up to $6000 \mathrm{~K}$ and high levels of evaporation caused significant erosion in form of continuous fine-spray of microscopic $\mathrm{W}$ droplets. In addition, splashing occurred several times during the melt phase ejecting droplets in the order of up to $100 \mu \mathrm{m}$ probably caused by an instability evolving in the melt layer. The formation of leading edges by redistributed melt, bubble formation and re-crystallization led to a severe material and power-handling degradation. As a consequence melting of $\mathrm{W}$ in ITER and next step devices is highly unfavourable and must be seen as a high risk in light of uncontrolled transients.

A limitation of the melt experiments using a limiter is the large incident angle of the power and the particles. Moreover the impact of the melt event in the main chamber on further plasma operation may be different from that of a melt event in the divertor. Therefore controlled tungsten melting experiments were initiated in AUG by exposing a W pin at the outer target plate to H-Mode discharges [80, 81]. Ejection of molten tungsten droplets was observed with typical lifetimes of $0.1 \mathrm{~s}$ and flight path lengths in the range of meters. The ejected droplets have a diameter in the range of 50-100 $\mu \mathrm{m}$, as those observed in TEXTOR. The divertor retention of the evaporated fraction of the eroded W-pin was determined to be in the range 1020, similar to that of $\mathrm{W}$ atoms eroded at the target plates [43]. Further experiments are being performed in ASDEX Upgrade investigating the behaviour of exposed edges of W castellated structures. However, for a quantitative extrapolation of both surface damage and tungsten penetration to the core plasma following melt ejection, the influence of the much higher ELM power and particle flux and the longer ELM repetition time expected in ITER must be taken into account by the respective models. Moreover the forces acting on the melt layer and the droplets will be different, because the plasma pressure will be much more dominant. In addition, the expected depth of the melt layer caused by transients will also be smaller [79], which also might influence its evolution.

If tungsten is not the only PFM in a tokamak, mixed material effects could influence the performance of the W PFCs. One obvious example for such an effect which has received a lot of attention is the formation of a low melting Be-W alloy as observed in PISCES-B [82]. The formation of the alloy depends delicately on the amount of $\mathrm{Be}$ in the plasma, the plasma conditions leading to either deposition of Be or a steady erosion of $\mathrm{W}$, and on the surface temperature which strongly influences the Be diffusion into $\mathrm{W}$ and its sublimation 
$[83,84,85]$ narrowing the window for its production considerably. Although no formation of Be-W alloys is predicted for ITER under steady state conditions, it cannot be excluded that during temperature excursions the diffusion can be strong enough to lead to the formation of $\mathrm{Be}$ rich $\mathrm{Be} / \mathrm{W}$ alloys in some locations (e.g. the inner divertor leg) [85]. The complexity of this process requires further experimental investigations and accompanying modelling in order to reduce the residual uncertainties in its potential impact.

\section{Compatibility of the PFC solution with requirements for plasma performance}

\subsection{Transport and Suppression of Central W Accumulation}

Apart from its dependence on the source, the central impurity concentration depends strongly on transport which can be divided in the region of open field lines, the so called scrape off layer (SOL) and the confined plasma. Experimental investigations of impurity transport in the SOL region are scarce and rather indirect. By use of a sublimation probe, the same amount of $\mathrm{W}$ was injected in the divertor and at the midplane SOL of ASDEX Upgrade [43]. By comparing the amount of tungsten found in the confined plasma region arising from these to source locations a divertor retention of 16 could be extracted in a medium density H-mode discharge, which is in line with the observation described in the previous section and similar to results from Alcator C-Mod [41].

In H-modes, one has to subdivide the confined plasma into the pedestal and core region. In the reactor relevant regime of type-I ELMs, the pedestal, with its steep pressure gradient, breaks down during an ELM and a substantial part of the pedestal plasma is ejected. In between ELMs, tungsten is transported into the pedestal region due to strong collisional inward particle drift $[86,87]$. If the ELM frequency is high enough, the tungsten is removed, before further penetrating towards the central plasma. The beneficial effect of frequent ELMs on the reduction of the $\mathrm{W}$ confinement time has been studied in detail in [40]. In AUG, the ELM contribution to the erosion of $\mathrm{W}$ does not depend on the energy loss during an ELM, i.e. less frequent larger ELMs cause the same influx as more frequent smaller ELMs. The heuristic picture described above was substantiated with edge transport modelling, where the impurity confinement time shows a strong decrease with increasing ELM frequency [40]. An increase of the ELM frequency and a reduction of the $\mathrm{W}$ content can also be achieved by external means, either by an increased gas puff rate or by so called ELM pace making $[88,89,90]$ (see next subsection). Since in the edge transport barrier of ITER, the collisional impurity diffusion coefficient is expected to be about a factor of 20 smaller than in ASDEX Upgrade [40], the time to build up a strong edge gradient is substantially longer. However, since the ELM frequency has to be kept high (around $20-30 \mathrm{~Hz}$ ) [91] in order to achieve an ELM size acceptable with regard to divertor lifetime the average edge peaking of $\mathrm{W}$ will be quite small in ITER [40]. These results do however suggest that total suppression of ELMs might not be desirable unless the flushing effect is replaced by an alternative loss process for high $\mathrm{Z}$ impurities (see next subsection).

The increased W-influx during ICRH (see Sec. 2.1) was used as diagnostic tool for the 
investigation of the $\mathrm{W}$ edge transport for different plasma configurations. For this purpose the ICRH power was modulated at a frequency of $10 \mathrm{~Hz}$ and the harmonic behaviour of the $\mathrm{W}$ source and the $\mathrm{W}$ emission at different plasma radii (emitted from different ionisation stages) was evaluated. Surprisingly, no strong change in the $\mathrm{W}$ edge transport was found for different gas puff rates and triangularities [92].

In the core plasma, an inward particle drift can lead to accumulation in the centre. In a simple picture, the diffusion consists of an anomalous and a neo-classical part $D=$ $D_{a n}+D_{\text {neo }}$. Recently it has been shown that $D_{a n}$ is only weakly $Z$ dependent and that the anomalous convective part is usually very small for higher $Z$ [93]. Therefore the convective contribution is assumed to be purely neoclassical with $v=v_{\text {neo }}$. If the deuterium density profile is not particularly flat this leads, in general, to accumulation of high- $Z$ elements in the core. The neoclassical accumulation has been experimentally observed in several devices $[94,90,95,96,97]$. However, if the heat flow in the core is sufficiently high, anomalous transport can easily exceed the neoclassical effects. First hints for a beneficial influence of central ICRH on the central radiation where already seen in $\mathrm{W}$ test-limiter experiments in TEXTOR [98]. However, the effect of central heating reducing central impurity accumulation by stimulating anomalous transport was first identified in ASDEX Upgrade [99] and the recipe was confirmed in several other devices [97, 100, 101, 102]. The effect is clearly seen in Fig. 3 , where the peaking of the $\mathrm{W}$ concentration reacts within the particle transport time on the different heating profiles provided by different mixtures of NBI and ICRH.

\subsection{Towards an integrated scenario}

In present day devices, plasma scenarios are optimized to reach specific and often narrow goals. In ITER the plasma scenarios have to fulfil all boundary conditions simultaneously, meaning that optimized confinement properties (good energy confinement - moderate impurity confinement), acceptable steady state power loads and strongly mitigated ELMs have to be achieved simultaneously. Independent of the used PFMs in ITER, impurity seeding will become an essential element of operation to protect the divertor from excessive heat loads [103]. Introducing low- $Z$ to mid- $Z$ impurities has also an impact on the erosion, especially that of a high- $Z$ material, which is predominantly sputtered by the impact of impurity ions which have more efficient momentum transfer to surface atoms (see Sec. 2.1). The effective erosion flux will result from a delicate interplay between the increased flux of impurity ions and the reduction of sputtering yield due to the lowered divertor plasma temperature. At the same time the seed impurity concentration in the plasma core must be kept at a tolerable level. Optimisation of the divertor impurity enrichment and the radiation distribution between core, SOL and divertor might be required to resolve the issue for devices with high values of $\mathrm{P} / \mathrm{R}$ (ratio of loss power and major radius). Another important constraint is the fact that the seeding scenario must be integrated into a small ELM regime or combined with ELM mitigation techniques.

After the change to a complete coverage with W PFCs and efficient suppression of oxygen by boronisation, impurities had to be injected deliberately in AUG high power discharges for 


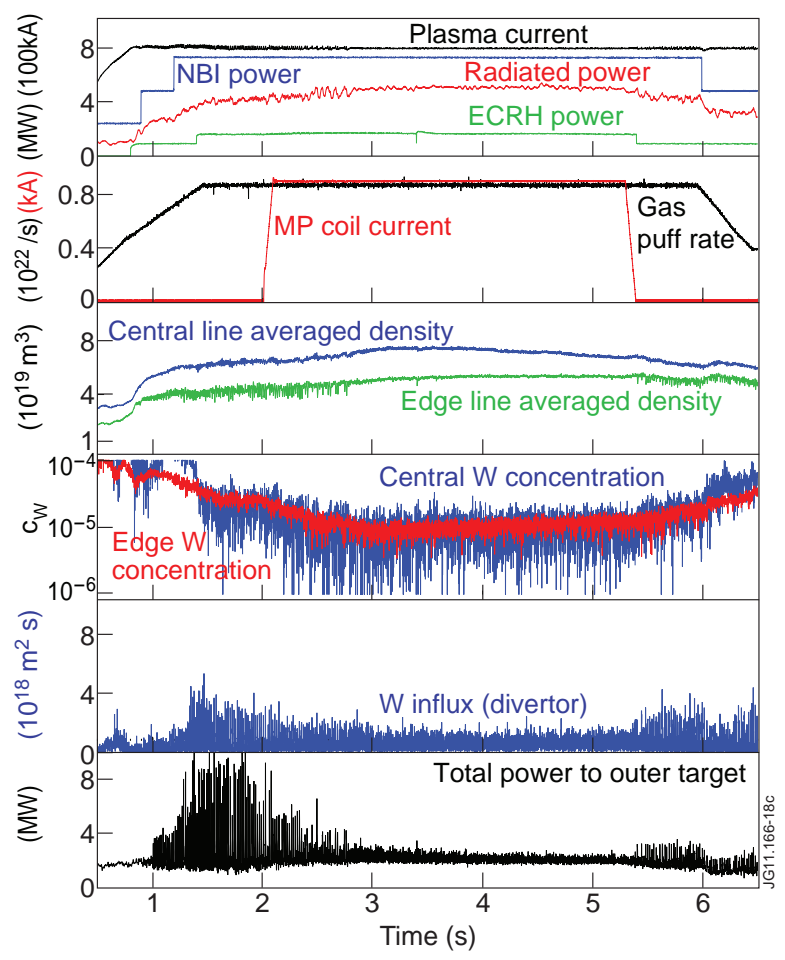

Figure 5. Divertor $\mathrm{W}$ influx and $\mathrm{W}$ concentration in ASDEX Upgrade during an ELMmitigated H-Mode (\#26081) with the use of magnetic perturbation (MP) coils.

radiative cooling. Amongst the different species used, nitrogen has been shown to provide the best cooling effect in ASDEX Upgrade discharges, while maintaining or even improving the energy confinement [104]. Depending on the background plasma density and the set divertor temperature a reduction or increase of the $\mathrm{W}$ sputtering yield compared to the unseeded phases was observed. An almost complete extinction of the W I intensity can be obtained by a simultaneous increase of the $\mathrm{D}$ and the $\mathrm{N}_{2}$ puffing rate. The increased $\mathrm{D}$ puffing rate can also lead to a transition to the type III ELM regime reducing the ELM size further [34].

In ITER, injection of low-Z impurities will probably not be sufficient to radiate a sufficient amount of power in the main chamber since the necessary (low) plasma temperatures are restricted to a too small volume. Therefore, the injection of an impurity mixture is envisaged [105]. Experiments with Ne/Ar [106] and N/Ar mixtures [107] have started, however further work is needed to extrapolate to ITER.

It has been shown earlier that pellet ELM pacemaking is consistent with radiative cooling scenarios allowing a reduction of both the steady state and the transient power loads [88]. Mitigation of ELMs by increasing the overall edge transport with edge magnetic field perturbations as pioneered by DIII-D [108, 109] and JET [110, 111], may also be a solution. However, a common feature of these experiments is the tendency for the separatrix temperature increases during the ELM suppression phases, which is consistent with an increase of $Z_{e f f}$ compared to similar discharges without edge perturbation as reported by [112] and which would be counter productive in the case of high-Z PFCs.

With the newly installed 8 magnetic perturbation (MP) coils at the low field side of AUG 
comprehensive investigations of ELM mitigation / suppression were performed. In all discharges with successful ELM mitigation the residual core tungsten concentration is at the same level or lower than in comparable type-I ELMy phases [113, 114]. In Fig. 5 a typical Hmode discharge with mitigated ELMs is shown. This can be judged from the strongly reduced transient power loads at the outer target (lowest time trace) as well as from the W influx at the outer strike-point. The latter one indicates sensitively the divertor plasma temperature $\left(T_{e}\right)$ during the ELMs through its strong $T_{e}$ dependence. The $\mathrm{W}$ concentration stays low and flat (same value for central and edge $c_{W}$ ) throughout the full mitigated phase. In addition, even in certain L-Mode discharges a reduction of $c_{W}$ of up to factor of 3 is observed [115]. First simulations using the EMC-3 code point to the fact that the reduction of $c_{W}$ is due to changes in the edge transport caused by the disturbed magnetic topology [116].

\section{The JET ITER-like wall project}

\subsection{Implementation of the JET ILW}

The ITER-like Wall (ILW) Project has the objective to mimic as close as possible the choice of PFM in the active phase of ITER $[2,117]$. Therefore all the existing CFC tiles in direct contact with the plasma were replaced with beryllium as the dominant main chamber material and with tungsten surfaces in the divertor [118]. In order to keep the conversion manageable, the impact of the materials changes on JET operational limits and work with the existing support structures had to be minimized. In the main chamber this was achieved by using bulk beryllium on Inconel carriers for the limiters and with tungsten coated CFC [119] in some higher heat flux recessed areas, for example the neutral beam shine through areas, and beryllium coated Inconel elsewhere [120]. The divertor consists of W-coated CFC tiles [121] and a single toroidally continuous belt of bulk tungsten at the outer strike point [122] (see figure 6). Besides this obvious reconstruction a large amount of details had to be changed/optimized [11]. For example, the upper dump plate now consists of Be ribs with beryllium coated Inconel plates between, rather than a continuous sheet of tiles. Furthermore, half the inner wall guard limiters have recessed centre sections clad with W-coated CFC or Be coated Inconel to maintain the power handling in NBI shinethrough areas and decouple it from plasma loads and the main limiters on the low field side of the machine (wide poloidal limiters) have optimised large format tiles. The anticipated operating limits with the ILW are most fundamentally driven by the relatively low melting point of beryllium $(1629 \mathrm{~K})$, the limited robustness of tungsten coatings to slow and fast thermal cycles and the thermal capabilities of the support structures for the bulk tungsten tile [123].

The protection of the ILW was an integral part of the project from very early on. In order to achieve PFC temperature measurements in real time, a comprehensive set of bi-colour pyrometers (8) and monochrome video cameras (7) with adjustable filters and thermo-couples was installed. Together with the appropriate software a fast reaction of the discharge control will be possible and a detailed map of the energy deposition on the PFCs can be established. 


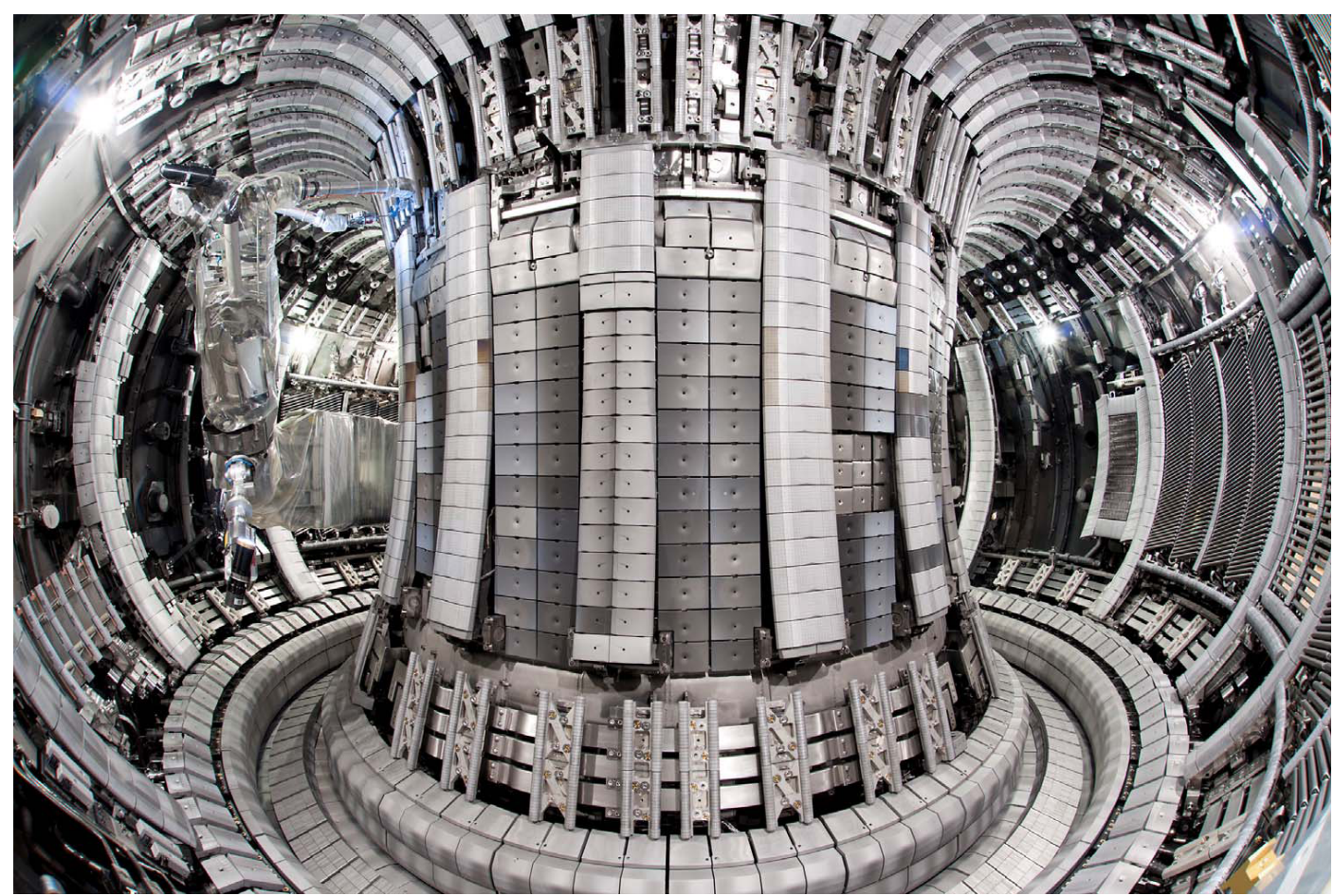

Figure 6. View into the interior of JET with all Be and W PFCs at the end of shut down in May 2011.

\subsection{The ILW programme during $2011 / 2012$}

The first part of the 2011/12 JET experimental programme is already well defined and the scientific teams are formed. A phased approach early in the programme will allow for specific investigations on the basic materials and fuel retention questions whilst minimising the risk associated with operation in an all metal machine. The JET upgrades also include an increase in neutral beam heating power, up to $35 \mathrm{MW}$ for $20 \mathrm{~s}$ [124], which requires real time monitoring of the most critical first wall Be and $\mathrm{W}$ components by an appropriate imaging protection system and thermocouples to unambiguously monitor the bulk temperature of critical tiles. These tools should allow the safe expansion of the operating space towards $\mathrm{H}$ Modes at similar power levels as those with the carbon walls and beyond, without hampering the interpretation of the long term samples which are planned to be removed in a 2012 intervention. Specifically, macroscopic melting should be avoided not to derogate the unique possibility to investigate the initial migration of $\mathrm{Be}$ and $\mathrm{W}$ due to plasma erosion.

In general, the program is aligned along headlines which were identified by the European fusion community to be of largest priority for JET operation in support of ITER. They are as follows (in order of descending priority):

- Characterisation of the ITER-like Wall,

- Exploration of ITER operating scenarios with the ITER-like Wall, and

- Physics issues essential to the efficient exploitation of the ILW and ITER.

In contrast to earlier JET campaigns the whole 2011/12 programme will be much more gradual in expanding performance with commissioning (restart) phases interleaved with 
scientific exploitation as new capabilities such as protection systems and heating power are released. The programme will progress from ohmic plasmas to L-mode then to H-mode expanding the injected power and the plasma current. Finally the hybrid scenario will be developed, going hand in hand with exploring the material questions, and the set-up of ELM mitigation and steady-state power load mitigation techniques. If the real time protection systems are mature enough in the second half of the operational campaign the injection of power (not energy) exceeding the one achieved in earlier campaigns ( $>30 \mathrm{MW}$ ) is foreseen. Exploration of ITER relevant issues will also begin right from the machine conditioning phase through to the first plasma. The first two week of operation will study material migration with a pristine wall which is a unique opportunity to start from well defined surface condition prior to mixing. A remote intervention into the vessel is planned in the second half of 2012 whose primary purpose is to remove long term samples for analysis. In the outline plan for the run up to this intervention, two weeks of JET H-mode operation under constant plasma conditions are scheduled $(\approx 2000$ s of divertor operation). The aim here is to build up sufficiently thick deposits / fuel inventory that surface analysis will be capable of resolving them and link them to a specific ITER-relevant scenario. Although the behaviour of melt layers and their influence on subsequent operation is one of largest concerns in ITER, intentional melt experiments will only be performed in JET in 2013 since their impact on the very limited amount of experimental time - due to a possible long down time - was regarded to be too severe.

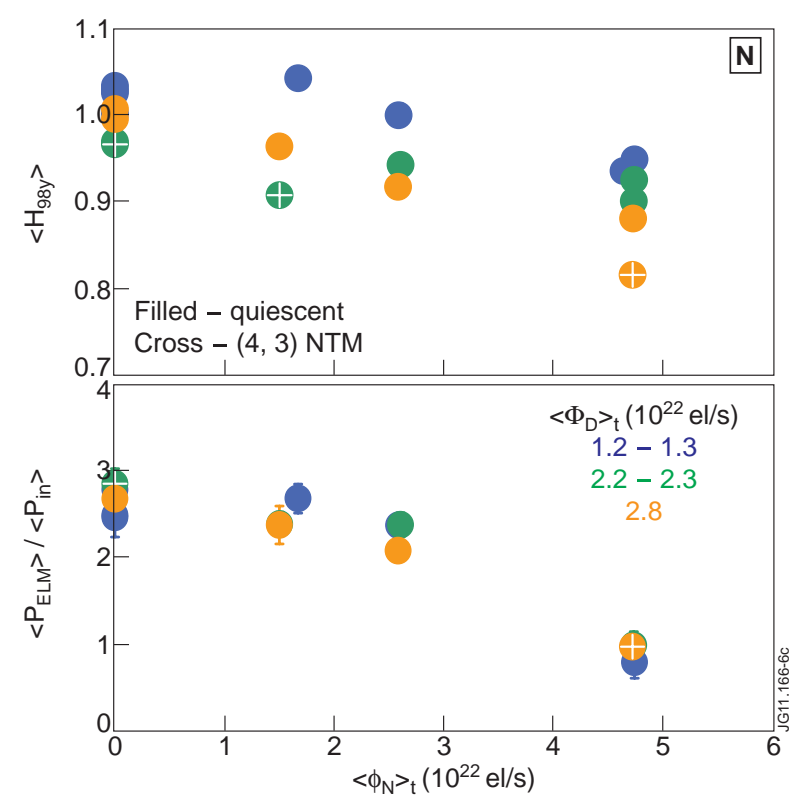

Figure 7. Effect of $\mathrm{N}_{2}$ seeding on the confinement and the ELM power deposition in JET discharges with different $\mathrm{D}$ puffing rate. The value $\left\langle P_{E L M}\right\rangle /\left\langle P_{\text {in }}\right\rangle$ denotes the ratio of the average power onto the outboard target over 10 largest ELMs over the averaged injected power during the time interval under consideration. The discharges were performed at $B_{t}=2.7$ $\mathrm{T}, I_{p}=2.5 \mathrm{MA}$ and an auxiliary heating power in the range 14 - $17 \mathrm{MW}$ (figure adapted from [125]). 


\subsection{Preparatory work for an efficient exploitation of the JET ILW}

Already in the preceding campaigns preparatory experiments for the operation and exploration of the ITER-Like Wall were performed [126]. These experiments aimed on the one hand for techniques to ensure ILW compatible operation and on the other hand for reference plasmas for a comparison of the $\mathrm{C} / \mathrm{Be}$ with the $\mathrm{Be} / \mathrm{W}$ wall with respect to material migration to remote areas and fuel retention. Global migration has been characterised by either tracer injection of carbon-containing species or strong Be evaporation, confirming in both cases the major erosion source in the main chamber and the flow of eroded particles in the SOL towards the divertor (see below). The layer deposition and the stepwise transport to remote areas is stronger at the inner divertor leg than at the outer one. Gas balance measurements for a large variety of plasma conditions (L-Mode, Type I and III ELMy H-Modes) has been carried out revealing very similar retention rates in the range of $1.0-2.0 \cdot 10^{21} \mathrm{Ds}^{-1}$ [127].

Reference discharges have been taken to document the $\mathrm{Be}$ and $\mathrm{C}$ sources, concentrations, divertor fluxes and deposition rates in remote areas for ohmic, L-mode and H-mode plasmas. The data base spans a matrix which allows a comparison of either discharges or matching of parameters such as divertor densities or temperatures [126]. Depending on the results for the hydrogen retention, investigations on hydrogen removal will become an important issue. In the framework of the coordinated approach pursued in [63], experiments on ion cyclotron wall cleaning have been already performed and optimized for JET conditions.

When designing discharges with the ILW, the main compatibility requirements are

- amelioration of steady-state power/energy loads,

- ELM control to inhibit critical transient loads, and

- W-source control to ensure sufficient lifetime.

The combination of impurity seeding and fuelling, which is necessary to mitigate the interELM power/energy load provides further synergetic benefits. In particular, cold divertor operation, which is required to inhibit physical W sputtering. These techniques can also produce a small ELM regime [125] and the comparison of different ELM-control techniques has shown that the means by which small ELMs are generated does not affect the result $[128,129]$. Control of the W-source control requires both cold divertor operation in the interELM phase as well as during the ELM and could be achieved by high density operation. Impurity seeding without additional fuelling was not sufficient to achieve divertor cooling down to partial detachment and load mitigation, thus, fuelling is mandatory for compatibility with the ILW. Therefore a high-density regime with strong $\mathrm{N}$ seeding which combines partial detachment at the outer strike-point and natural ELM mitigation with only moderate reduction in plasma confinement of 10-15\% has been developed as an integrated scenario with full ILW compatibility for highest input power (see Fig. 7). In this regime, the divertor temperature will be sufficiently low with $T_{e}<6 \mathrm{eV}$ to inhibit physical sputtering, the peak power load will stay below $2 \mathrm{MWm}^{-2}$, and ELMs will be mitigated to energy losses of a less than $100 \mathrm{~kJ}$. Active ELM control will be utilised as a back-up system to avoid critical excursions of the ELM energy in case of inefficacy of the gas injection. Finally, strike-point sweeping will be applied to prolong the steady-state phase on the fourfold-segmented bulk-W plate [122]. 
Before using nitrogen as a standard gas for radiation cooling, it had to be checked whether there are adverse effects to be expected in connection with the Be main chamber PFCs. This question has been addressed at the PISCES-B linear plasma by admixing $\mathrm{N}_{2}$ to the $\mathrm{D}_{2}$ working gas [130]. These studies have shown no evidence for the creation of strong insulating beryllium-nitride layers at the target and recovery from the nitrogen loaded surfaces was possible by pure $\mathrm{D}$ operation. The amount of $\mathrm{D}$ retention was found to be similar as in cases without nitrogen, but the nitride shifts the release of $\mathrm{D}$ to higher temperatures. Similar to the transient power load by ELMs the power load during disruption potentially could damage the Be and W PFCs. Recent experiments with a massive gas injection valve injecting mixtures of noble gases and deuterium showed that the heat load during the thermal quench was reduced by enhanced radiation, which could amount about $50 \%$ to almost $100 \%$ of thermal energy, depending on the analysis method [131]. The poloidal and toroidal peaking of the induced radiation was small during a large part of the mitigation process and no local Be melting due to thermal overload by the induced radiation is therefore expected.

As described in Sec. 4.1, W coated CFC tiles have to be used in shine through areas. To quantify the impact of the $\mathrm{W}$ influx produced by fast particles from the beams, detailed calculation were performed taking into account the beam composition and its specific attenuation by the plasma, the sputtering yield and its variation with incidence angle, as well as the increased penetration of the sputtered $\mathrm{W}$ atoms due to their high energy Thompson distribution [132]. It turns out that the $\mathrm{W}$ content resulting from the sputtering at the beam shine through areas should be negligibly small. The predicted $\mathrm{W}$ density increase per injected MW is only about $5 \cdot 10^{13} \mathrm{~m}^{-3}$ at the lowest accessible plasma densities, decreasing strongly with increasing density. On the other hand, if the background $\mathrm{W}$ density resulting from the $\mathrm{W}$ divertor source turns out to be low enough, the $\mathrm{W}$ influx from the high field side could be used for transport experiments using beam modulation, similar to the experiments performed with ICRH modulation in AUG [92].

The migration of $\mathrm{Be}$ from the main chamber into the divertor was investigated in a series of L-Mode discharges preceded by massive Be evaporation, where 50 times more Be was evaporated compared to regularly performed standard evaporations for conditioning [133]. The modelling of such long term material re-distribution requires an iterative approach that takes the local erosion, the global transport of material by the scrape-off layer (SOL) plasma and the local re-deposition into account [134]. The used model combines parameterized DIVIMP calculations and a simplified sputtering model. The temporal evolution of the spectroscopically measured Be erosion fluxes for $800 \mathrm{~s}$ total plasma time at the main wall and inner divertor could be reproduced by the model using an extended calculation grid for DIVIMP and an increased cross-field diffusivity for impurity ions in the SOL. Discrepancies were found in the outer divertor region, where the predicted erosion and consequently the decay rate of the influx is too large. Using this benchmark, the model was applied to predict the initial migration of Be and W [135] in L-Mode Plasmas. As expected Be is mainly eroded at the inner main wall and is deposited above the inner strike point, whereas $\mathrm{W}$ is deposited at the inner strike point. No indications for significant Be/W-alloy co-deposits were found. In another experiment with massive Be evaporation, the $\mathrm{H}$-retention was investigated in $\mathrm{N}$ 
seeded H-Mode discharges $\left(B_{t}=2.7 \mathrm{~T}, I_{p}=2.5 \mathrm{MA}, P_{a u x}=16 \mathrm{MW}\right)$ [136], which will be used similarly in the upcoming campaign. Although residual gas analysis revealed a reduction of hydrocarbons by one order of magnitude and of oxygen by a factor of 5 , the $\mathrm{C}$ flux in the limiter phase of the first discharge decreased only by $\approx 50 \%$. The $\mathrm{D}$ retention rate of $\approx 2 \cdot 10^{21}$ $\mathrm{Ds}^{-1}$ is very similar to the rates with $\mathrm{C}$ walls (see above), but the retention in the non-saturated Be layers probably is not negligible in this balance.

DIVIMP simulations deal with the ELM resolved modelling of $\mathrm{W}$ erosion in the divertor during radiatively cooled medium power H-Modes [137] using 2D background plasmas from the coupled edge and core simulation code JINTRAC [138]. Due to a high divertor leakage at low densities, an average core tungsten concentration in the range of $10^{-5}$ is predicted.

The effect of ICRH on the behaviour of mid-Z (Ni) and high-Z (Mo) impurities in the plasma centre was recently investigated in JET [102]. A scan of centrally deposited ICRH power in low collisionality $\mathrm{H}$-mode discharges has confirmed that a few MW can avoid the formation of peaked Ni and Mo profiles. Although the exact mechanism providing this effect could not be unambiguously identified, there is a strong anti-correlation of the impurity peaking with the logarithmic ion temperature gradient suggesting that the flattening effect is of neoclassical origin.

\section{Summary}

Tritium retention in pure W PFCs seems not to be a problem throughout the design life-time of ITER even when taking into account effects of n-irradiation. In DEMO elevated temperatures (above $870 \mathrm{~K}$ ) are envisaged for the PFCs to keep the effects of the neutron irradiation low. This in turn will keep the tritium inventory low enough, but will lead to a new class of problems arising from the diffusion of $\mathrm{T}$ to the cooling medium. Although, retention of implanted $\mathrm{T}$ is also small the role of $\mathrm{T}$ co-deposition with Be still has many uncertainties. Although, retention of implanted $\mathrm{T}$ is also small the role of $\mathrm{T}$ co-deposition with Be has to be assessed. Not only the $\mathrm{T} / \mathrm{Be}$ ratio varies quite considerably depending on deposition conditions, but also the measured effective Be erosion rates vary by a factor of 100, when comparing the results of investigations in accelerators, PISCES-B and JET.

Accidental melting of metallic PFC and its impact on subsequent plasma operation remains one of the largest concerns. The difficulty in these investigations is the qualification of a relevant melt event. This is true not only for the temporal and spatial evolution of the melt layer but also for the absolute size of the melt event: if it is too small no consequences for the plasma are observed, but if it is too large the melt event will not only hamper plasma operation but eventually it will also lead to a complete failure of the actively cooled PFC and has to be prevented by any means.

The suppression of central impurity peaking and or accumulation by central heating has proven to be a robust effect in all major devices. The theoretical understanding is still a matter of current research, but current predictive modeling seems to be rather promising for the high$\mathrm{Z}$ impurity behaviour in ITER especially since neoclassical effects should play a much less pronounced role compared to present day devices. In addition to central impurity transport, 
transport in the edge transport barrier has to be controlled. As long as the ELM frequency is high enough (depending on the discharge scenario and the device) the flushing of the impurities from the edge plasma by the ELMs is more efficient than the additional source due to the increased power and particle flux during the ELM (as has been qualitatively observed since long in quiescent ELM-free H-modes, which regularly are terminated by a radiation collapse). The requirement for small ELM regimes in ITER with acceptable power loads, goes hand in hand with increased edge transport for impurity flushing. Whereas this has been shown earlier for the tools increased gas-puff and pellet ELM pace making, it could be shown only recently in AUG that also the application of resonant magnetic field perturbation provides the means for strongly suppressed ELMs combined with a beneficial edge transport for heavy impurities as W. The open question is which of these ELM control techniques can best be scaled to the physics parameters which will be found in ITER. In present day devices it is difficult to achieve ITER-like pedestal and central plasma in combination with a W-compatible SOL and divertor plasma. Nevertheless efforts have to be pursued to verify the applicability of the experimental results achieved so far for ITER conditions. It has to be pointed out that in these kind of plasmas the achievement of $\mathrm{W}$ concentrations sufficiently low for ITER burn conditions is not a valid criterion as long as the $\mathrm{W}$ radiation does not affect the discharge behaviour (similarly to the investigation with low-Z PFCs, where mostly the ambient $Z_{e f f}$ is not in the range necessary for ITER).

Impurity production by ICRH with high Z PFCs is still an unsolved problem but ideas for the reduction of rectified sheaths in front of the antenna are currently developed and will be implemented soon in devices as ASDEX Upgrade or Alcator C-Mod. It has to be noted however, that although the $\mathrm{W}$ erosion and its consecutive transport into the confined plasma presently leads to unacceptable high W concentrations, it strongly suggests that that traditional antenna designs will not be a solution in future long duty cycle devices due to the strongly enhanced erosion irrespectively of the used PFM itself. Reducing the intrinsic radiation either by removing low-Z PFCs completely or by using only Be and $\mathrm{W}$ as foreseen in the active phase of ITER, increases the need for radiative scenarios in ITER, but makes them also indispensable in present day devices in high power scenarios. Results gained in ASDEX Upgrade so far using nitrogen as seeding gas are very promising. Even a complete suppression of the W erosion in the divertor could be achieved maintaining acceptable energy confinement and core dilution, although this beneficial behaviour could not be reproduced in other devices yet.

\section{Conclusions and Outlook}

Following the above summary one can conclude that potential solutions for many of the problems associated with a change to all metal PFCs have been demonstrated during the last decade. However, compared to the comprehensive knowledge the fusion community has gathered with carbon based PFCs there has still not been sufficient confidence to trigger the change to an all metal ITER first wall for the low activation phase. In preparing the basis for the removal of the CFC divertor PFCs from ITER, the JET ILW will play a key role coming 
closest in wall configuration and plasma parameters of ITER. An important question will be whether the hydrogen retention is reduced strongly enough compared to the well documented cases with all C PFCs in JET. If this is not the case special emphasis has to be given to development of retained fuel removal methods compatible with the Be PFCs. Other very important aspects, which can only be investigated under relevant conditions in JET are the compatibility of Be and W PFCs and the development of integrated radiative scenarios close to ITER. Although the behaviour of melt layers and their influence on subsequent operation is one of largest concerns in ITER, intentional melt experiments will only performed in JET 2013 due to the very limited amount of experimental time available in 2011/2012 campaigns. The progress in development and understanding of all metal PFCs provides an excellent example of why multiple facilities with different focus and capability are needed to progress this technology and the science that underpins it. TEXTOR has taken the lead in melt experiment providing important data for benchmarking of codes [12] although not completely relevant due to the rather steep angle of plasma incidence. A closer match will be possible in AUG using a melt probe in the divertor and when bulk W tiles will be implemented at the outer strike-point in 2012 [139]. Further investigations using the full capabilities of the MP coils available in AUG at the end of 2011 will give further insight into the compatibility of this ELM mitigation method with W PFCs. On a longer time scale the use of 3-strap antennas is proposed in AUG, which will allow a better compensation of the HF electrical field at the antenna edges.

Whereas JET is unique for the use of Be PFCs, the use of large area W PFCs is envisaged in several devices. The Chinese super-conducting tokamak EAST plans the complete removal of C based PFCs and the use of actively cooled W-PFCs from 2013 on [140]. Very recently, CEA Cadarache has presented a proposal for a major reconstruction of Tore Supra [141] implementing a divertor which would be equipped with actively cooled W mono-blocks of the same technique as envisaged for ITER. Both devices would primarily address technological issues arising from the use of actively cooled W PFCs. Besides these mid-term plans, and the possible extension of the JET campaigns beyond 2013, which would allow the test of the ILW in a DT campaign planned in 2014/2015 [142], the Italian proposal for a European ITER satellite FAST [143] foresees a complete coverage by W PFCs by W mono-blocks in the divertor and $\mathrm{W}$ coated steel tubes in the main chamber. JT60-SA, which is part of the 'broader approach' pursued in collaboration between Japan and Europe, is currently planning to use carbon based PFCs at least in an initial phase changing to W coated PFCs only at a later stage (after 2022) [144]. In parallel to the use of the ITER materials in fusion devices, high repetition / high fluence testing in laboratory devices has to be pursued in view of DEMO which requires higher temperatures for the PFCs and may use special grades or alloys of tungsten. Investigations of the behaviour of n-irradiated PFCs and PFMs a new area which has to be thoroughly addressed if a fusion reactor is to be realised. Specifically, for investigations on the behaviour of n-irradiated PFCs and PFMs mark a new area to be entered. At the moment, the capabilities in this area are rather limited, but FZ Jülich has started an initiative to set-up a linear plasma device in a hot cell [145] enabling, together with the JUDITH facility [5], substantial research on activated materials and components. 


\section{Acknowledgement}

The author wants to thank the colleagues from ASDEX Upgrade, the EU PWI Taskforce and from EFDA JET, for providing their latest results. This work was supported by EURATOM and carried out within the framework of the European Fusion Development Agreement. The views and opinions expressed herein do not necessarily reflect those of the European Commission.

\section{References}

[1] R. Neu, M. Balden, V. Bobkov, R. Dux, O. Gruber, et al., Plasma Physics and Controlled Fusion 49(12B), B59-B70 (2007).

[2] J. Pamela, G. Matthews, V. Philipps, and R. Kamendje, J. Nucl. Mater. 363-365, 1 - 11 (2007).

[3] V. Philipps, J. Roth, and A. Loarte, Plasma Physics and Controlled Fusion 45(12A), A17 (2003).

[4] R. Pitts, S. Carpentier, F. Escourbiac, T. Hirai, V. Komarov, et al., accepted for publ. in Journ. Nucl. Mater., http://dx.doi.org/10.1016/j.jnucmat.2011.01.114 (2011).

[5] J. Linke, F. Escourbiac, I. Mazul, R. Nygren, M. Rödig, et al., Journal of Nuclear Materials 367-370(Part 2), 1422 - 1431 (2007).

[6] G. J. van Rooij, Fusion Science and Technol. 57T, 313 - 319 (2010).

[7] G. J. van Rooij, V. P. Veremiyenko, W. J. Goedheer, B. de Groot, A. W. Kleyn, et al., Applied Physics Letters 90(12), 121501 (2007).

[8] G. D. Temmerman, J. Zielinski, S. van Diepen, L. Marot, and M. Price, Nuclear Fusion 51(7), 073008 (2011).

[9] R. Doerner, M. Baldwin, R. Conn, A. Grossman, S. Luckhardt, et al., Journal of Nuclear Materials 290-293, 166 - 172 (2001).

[10] R. Neu, V. Bobkov, R. Dux, J. C. Fuchs, O. Gruber, et al., Physica Scripta T138, 014038 (6pp) (2009).

[11] G. Matthews, M. Beurskens, S. Brezinsek, M. Groth, E. Joffrin, et al., presented at the 13th PFMC workshop, I-01, submitted to Physica Scripta (2011).

[12] J. Coenen, B. Bazylev, S. Brezinsek, V. Philipps, T. Hirai, et al., Journal of Nuclear Materials In Press, Corrected Proof, - (2011).

[13] A. Loarte, B. Lipschultz, A. S. Kukushkin, G. F. Matthews, P. C. Stangeby, et al., Nuclear Fusion 47(6), S203-S263 (2007).

[14] A. Loarte, M. Sugihara, M. Shimada, A. Kukushkin, D. Campbell, et al., ITER ELM Control Requirements, ELM Control Schemes and Required R\&D, in Proc. 22nd IAEA Fusion Energy Conf. 2008 (Geneva, Switzerland, 2008) (Vienna: IAEA) CD-ROM file IT/P6-13, 2008.

[15] R. Pitts, A. Kukushkin, A. Loarte, A. Martin, M. Merola, et al., Physica Scripta T138, 014001 (2009).

[16] R. Pitts et al., Physics basis and design of the ITER plasma-facing components, in this conference, invited talk I1.301, 2011.

[17] J. Roth, E. Tsitrone, A. Loarte, T. Loarer, G. Counsell, et al., J. Nucl. Mater. 390-391, 1-9 (2009).

[18] R. Neu, IEEE Transactions on Plasma Science 38(3), 453-460 (2010).

[19] V. Philipps, Journal of Nuclear Materials In Press, Corrected Proof, -(2011).

[20] J. Brooks, J. Allain, R. Doerner, A. Hassanein, R. Nygren, et al., Nucl. Fusion 49, 035007 (2009).

[21] W. Eckstein, C. García-Rosales, J. Roth, and J. Lázló, Nucl. Instr. Meth. B83, 95 (1993).

[22] J. Roth, J. Nucl. Mater. 266-269, 51 - 57 (1999).

[23] W. Eckstein, Computer Simulation of Ion-Solid Interaction, in Springer Series in Material Science, volume Vol.10, Berlin, 1991, Springer.

[24] J. Roth, W. Eckstein, and M. Guseva, Fusion Engineering and Design 37(4), 465 - 480 (1997).

[25] R. P. Doerner, A. Grossman, S. Luckhardt, R. Seraydarian, F. C. Sze, et al., Journal of Nuclear Materials 257(1), $51-58$ (1998). 
[26] T. Schwarz-Selinger, M. Baldwin, D. Nishijima, H. Xu, , et al., presented at the 13th PFMC workshop, I-19, submitted to Physica Scripta (2011).

[27] A. Hwang, M. Stamp, D. Summers, D. Elder, M. Forrest, et al., Journal of Nuclear Materials 176-177, $588-592$ (1990).

[28] M. Stamp, K. Krieger, and S. Brezinsek, Journal of Nuclear Materials In Press, Corrected Proof, (2010).

[29] S. Carpentier, R. Pitts, P. Stangeby, J. Elder, A. Kukushkin, et al., Journal of Nuclear Materials In Press, Corrected Proof, - (2010).

[30] D. Borodin, A. Kirschner, D. Matveeva, A. Galonska, V. Philipps, et al., presented at the 13th PFMC workshop, O-10, submitted to Physica Scripta (2011).

[31] W. Eckstein, C. García-Rosales, J. Roth, and W. Ottenberger, Sputtering Data, Rep. IPP 8/82, MaxPlanck-Institut für Plasmaphysik, Garching, 1993.

[32] A. Thoma, K. Asmussen, R. Dux, K. Krieger, A. Herrmann, et al., Plasma Physics and Controlled Fusion 39(9), 1487-1499 (1997).

[33] A. Kallenbach, R. Dux, J. C. Fuchs, R. Fischer, B. Geiger, et al., Plasma Physics and Controlled Fusion 52(5), 055002 (2010).

[34] R. Neu, A. Kallenbach, M. Sertoli, R. Dux, R. Fischer, et al., Journal of Nuclear Materials In Press, Corrected Proof, - (2010).

[35] A. Kallenbach, P. T. Lang, R. Dux, J. C. Fuchs, A. Herrmann, et al., Journal of Nuclear Materials 337-339, 732-736 (2005).

[36] R. Dux, V. Bobkov, N. Fedorczak, K. Iraschko, A. Kallenbach, et al., Journal of Nuclear Materials 363365, 112-116 (2007).

[37] D. Naujoks, K. Asmussen, M. Bessenrodt-Weberpals, S. Deschka, R. Dux, et al., Nuclear Fusion 36(6), 671-687 (1996).

[38] R. Dux, V. Bobkov, A. Herrmann, A. Janzer, A. Kallenbach, et al., Journal of Nuclear Materials 390-391, 858-863 (2009).

[39] S. Brezinsek, J. Coenen, M. Laengner, A. Pospieszczyk, U. Samm, et al., presented at the 13th PFMC workshop, P22A, submitted to Physica Scripta (2011).

[40] R. Dux, A. Janzer, T. Pütterich, and ASDEX Upgrade Team, Nuclear Fusion 51(5), 053002 (2011).

[41] B. Lipschultz, D. Pappas, B. LaBombard, J. Rice, D. Smith, et al., Nucl. Fusion 41, 585 - 596 (2001).

[42] B. Lipschultz, Y. Lin, E. Marmar, D. Whyte, S. Wukitch, et al., J. Nucl. Mater. 363-365, 1246-1250 (2007).

[43] A. Geier, H. Maier, R. Neu, K. Krieger, and ASDEX Upgrade Team, Plasma Physics and Controlled Fusion 44(10), 2091-2100 (2002).

[44] T. Pütterich, R. Neu, R. Dux, A. D. Whiteford, M. G. O’Mullane, et al., Plasma Physics and Controlled Fusion 50(8), 085016 (2008).

[45] R. Dux, R. Neu, A. G. Peeters, G. Pereverzev, A. Mück, et al., Plasma Physics and Controlled Fusion 45(9), 1815-1825 (2003).

[46] V. Bobkov, F. Braun, L. Colas, R. Dux, H. Faugel, et al., Journal of Nuclear Materials In Press, Corrected Proof, - (2010).

[47] R. Doerner, M. Baldwin, G. D. Temmerman, J. Hanna, D. Nishijima, et al., Nuclear Fusion 49(3), 035002 (2009).

[48] K. Sugiyama, K. Krieger, C. Lungu, and J. Roth, Journal of Nuclear Materials 390-391, 659 - 662 (2009).

[49] J. Roth and K. Schmid, presented at the 13th PFMC workshop, I-16, submitted to Physica Scripta (2011).

[50] A. Golubeva, V. Kurnaev, M. Mayer, and J. Roth, Hydrogen retention in plasma-sprayed tungsten, in In Hydrogen in Matter: A Collection from the Papers Presented at the 2nd International Symposium on Hydrogen in Matter, volume 837, American Insitute of Physics, 2006, AIP Conf. Proc.

[51] O. Ogorodnikova, J. Roth, and M. Mayer, J. Nucl. Mater. 313-316, 469-477 (2003).

[52] O. Ogorodnikova, J. Roth, and M. Mayer, J. Appl. Phys. 103, 034902 (2008).

[53] W. Wampler and R. Doerner, Nuclear Fusion 49(11), 115023 (2009).

[54] O. Ogorodnikova, B. Tyburska, V. Alimov, and K. Ertl, Journal of Nuclear Materials In Press, Corrected 
Proof, - (2010).

[55] U. von Toussaint, S. Gori, A. Manhard, T. Höschen, and C. Höschen, presented at the 13th PFMC workshop, submitted to Physica Scripta (2011).

[56] M. Mayer, V. Rohde, K. Sugiyama, J. L. Chen, X. Gong, et al., Journal of Nuclear Materials 390-391, 538-543 (2009).

[57] K. Sugiyama, M. Mayer, V. Rohde, M. Balden, T. Durbeck, et al., Nuclear Fusion 50(3), 035001 (8pp) (2010).

[58] V. Rohde, A. Kallenbach, V. Mertens, R. Neu, and ASDEX Upgrade Team, Plasma Physics and Controlled Fusion 51(12), 124033 (8pp) (2009).

[59] B. Lipschultz, D. Whyte, J. Irby, B. LaBombard, et al., Nucl. Fusion 49, 045009 (18pp) (2009).

[60] V. Rohde, V. Mertens, R. Neu, and ASDEX Upgrade Team, Dynamic wall loads measured by gas balance technique in all tungsten ASDEX Upgrade, in Proc. of the 23rd IAEA Fusion Energy Conference, Daejon, Korea Rep. of, volume IAEA-CN-180, pages EXD/P3-28, Vienna, 2010, IAEA.

[61] K. Sugiyama, J. Roth, A. Anghel, C. Porosnicu, M. Baldwin, et al., Journal of Nuclear Materials In Press, Corrected Proof, - (2010).

[62] A. Lyssoivan, R. Koch, J.-M. Noterdaeme, V. Philipps, D. V. Eester, et al., AIP Conference Proceedings 1187, 165-172 (jan 2009).

[63] D. Douai, A. Lyssoivan, V. Philipps, V. Rohde, T. Wauters, et al., Journal of Nuclear Materials In Press, Corrected Proof, - (2010).

[64] A. Haasz, M. Poon, and J. Davis, J. Nucl. Mater. 266-269, 520-525 (1999).

[65] W. Wang, J. Roth, S. Lindig, and C. Wu, J. Nucl. Mater. 299, 124-131 (2001).

[66] W. Shu, M. Nakamich, V. K. Alimov, G.-N. Luo, K. Isobe, et al., J. Nucl. Mater. 390-391, 1017 - 1021 (2009).

[67] M. Miyamoto, D. Nishijima, Y. Ueda, R. Doerner, H. Kurishita, et al., Nucl. Fusion 49, 065035 (2009).

[68] S. Takamura, N. Ohno, D. Nishijima, and S. Kajita, Plasma and Fusion Research 1, 051 (2006).

[69] M. Baldwin and R. Doerner, Nucl. Fusion 48, 035001 (2008).

[70] S. Kajita, W. Sakaguchi, N. Ohno, N. Yoshida, and T. Sae, Nucl. Fusion 49, 095005 (6pp) (2009).

[71] R. Doerner, M. Baldwin, and P. Stangeby, Nuclear Fusion 51(4), 043001 (2011).

[72] Y. Ueda, K. Miyata, M. Fukumoto, Y. Ohtsuka, S. Brezinsek, et al., Journal of Nuclear Materials In Press, Corrected Proof, - (2010).

[73] G. McCracken, Journal of Nuclear Materials 93-94, 3 (1980).

[74] A. Herrmann, M. Balden, M. Laux, K. Krieger, H. W. Müller, et al., Journal of Nuclear Materials 390391, 747-750 (2009).

[75] V. Rohde, N. Endstrasser, U. Toussaint, M. Balden, T. Lunt, et al., Journal of Nuclear Materials In Press, Corrected Proof, - (2010).

[76] V. Rohde, M. Mayer, V. Mertens, R. Neu, K. Sugiyama, et al., Nuclear Fusion 49(8), 085031 (9pp) (2009).

[77] N. Endstrasser, V. Rohde, M. Balden, U. v.Toussaint, M. Rampp, et al., Characteristics of different dust sampling techniques in view of the classification of particles from full-tungsten ASDEX Upgrade, in presented at the 13th PFMC workshop, P25B, submitted to Physica Scripta, 2011.

[78] J. Coenen, V. P. abd S. Brezinsek, B. Bazylev, A. Kreter, T. Hirai, et al., accepted for publication in Nuclear Fusion (2011).

[79] B. Bazylev, G. Janeschitz, I. Landman, A. Loarte, G. Federici, et al., J. Nucl. Mater. 390-391, 810-813 (2009).

[80] K. Krieger, T. Lunt, R. Dux, A. Janzer, A. Kallenbach, et al., Journal of Nuclear Materials In Press, Corrected Proof, - (2010).

[81] K. Krieger, T. Lunt, R. Dux, A. Janzer, S. Potzel, et al., invited talk presented at the 13th PFMC workshop, I-21, submitted to Physica Scripta (2011).

[82] R. Doerner, M. Baldwin, and R. Causey, J. Nucl. Mater. 342, 6367 (2005).

[83] M. Baldwin, R. Doerner, D. Nishijima, D. Buchenauer, W. Clift, et al., J. Nucl. Mater. 363 - 365, 1179 1183 (2007). 
[84] C. Linsmeier, K. Ertl, J. Roth, A. Wiltner, K. Schmid, et al., J. Nucl. Mater. 363 - 365, 1129 - 1137 (2007).

[85] K. Schmid, Nucl. Fusion 48, 105004 (2008).

[86] R. Dux, Fusion Science and Technology 44(3), 708-715 (2003).

[87] T. Pütterich, R. Dux, M. Janzer, R. McDermott, and ASDEX Upgrade Ream, Journal of Nuclear Materials In Press, Corrected Proof, - (2010).

[88] P. T. Lang, A. Kallenbach, J. Bucalossi, G. D. Conway, A. Degeling, et al., Nuclear Fusion 45(6), 502511 (2005).

[89] A. Kallenbach, R. Neu, R. Dux, H.-U. Fahrbach, J. C. Fuchs, et al., Plasma Physics and Controlled Fusion 47(12B), B207-B222 (2005).

[90] R. Neu, R. Dux, A. Kallenbach, T. Pütterich, M. Balden, et al., Nuclear Fusion 45(3), 209-218 (2005).

[91] A. Loarte, D. Campbell, Y. Gribov, R. Pitts, N. Klimov, et al., ITER ELM Control Requirements, ELM Control Schemes and Required R \& D, in Proc. 23rd IAEA Fusion Energy Conference 2010 (Daejeon, Korea, 2010) (Vienna: IAEA) CD-ROM file ITR/1-4, 2010.

[92] A. Janzer, R. Dux, T. Pütterich, and ASDEX Upgrade Team, Investigating Tungsten Transport in the Plasma Edge at ASDEX Upgrade, in Europhysics Conference Abstracts (CD-ROM, Proc. of the 37th EPS Conference on Plasma Physics, Dublin, Ireland, 2010), edited by C. McKenna, volume 34A of ECA, page P1.1046, Geneva, 2010, European Physical Society.

[93] C. Angioni, R. Dux, E. Fable, A. G. Peeters, and ASDEX Upgrade Team, Plasma Physics and Controlled Fusion 49(12), 2027-2043 (2007).

[94] J. Rapp, M. Tokar, L. Könen, H. Koslowski, G. Bertschinger, et al., Plasma Phys. Control. Fusion 39, 1615-1634 (1997).

[95] R. Dux, C. Giroud, K.-D. Zastrow, and contributors to the EFDA-JET work programme, Nuclear Fusion 44(2), 260-264 (2004).

[96] D. Pacella, K. Fournier, M. Zerbini, M. Finkenthal, M. Mattioli, et al., Phys. Rev. E 61, 5701 - 5709 (2000).

[97] J. E. Rice, P. Bonoli, E. Marmar, S. Wukitch, R. L. Boivin, et al., Nucl. Fusion 42, 510-519 (2002).

[98] R. Koch, A. Messiaen, J. Ongena, R. Van Nieuwenhove, G. Van Oost, et al., Fus. Eng. Design 26, 103 (1995).

[99] R. Neu, R. Dux, A. Geier, A. Kallenbach, R. Pugno, et al., Plasma Physics and Controlled Fusion 44(6), 811-826 (2002).

[100] W. West, M. Wade, C. Greenfield, E. Doyle, K. Burrell, et al., Physics of Plasmas 9, 1970 - 1981 (2002).

[101] T. Nakano, H. Kubo, N. Asakura, S. K., and S. Higashijima, Impurity accumulation in the main plasma and radiation processes in the divertor plasma of JT-60U, in Proc. of the 22th IAEA Conf. on Fusion Energy, Genf, Switzerland, October 2008, (CD-ROM), pages P-4.25, Vienna, 2008, IAEA.

[102] M. Valisa, L. Carraro, I. Predebon, M. Puiatti, C. Angioni, et al., Nuclear Fusion 51(3), 033002 (2011).

[103] A. Loarte, Physica Scripta 2004(T111), 13 (2004).

[104] O. Gruber, A. C. C. Sips, R. Dux, T. Eich, J. C. Fuchs, et al., Nuclear Fusion 49(11), 115014 (2009).

[105] A. Kallenbach, M. Balden, R. Dux, T. Eich, C. Giroud, et al., Journal of Nuclear Materials In Press, Corrected Proof, - (2010).

[106] N. Asakura, T. Nakano, N. Oyama, T. Sakamoto, G. Matsunaga, et al., Nucl. Fusion 49, 115010 (2009).

[107] R. Neu, J. Fuchs, A. Kallenbach, R. Dux, T. Eich, et al., Power and Particle Exhaust Control in All W ASDEX Upgrade, in Proc. of the 23rd IAEA Fusion Energy Conference, Daejon, Korea Rep. of, volume IAEA-CN-180, pages EXD/P3-24, Vienna, 2010, IAEA.

[108] T. Evans, R. Moyer, J. Watkins, T. Osborne, P. Thomas, et al., Nucl. Fusion 45, 595-607 (2005).

[109] T. Evans, M. Fenstermacher, R. Moyer, T. Osborne, J. Watkins, et al., Nucl. Fusion 48, 024002 (2008).

[110] Y. Liang, H. Koslowski, P. Thomas, E. Nardon, et al., Phys. Rev. Letters 98, 265004 (2007).

[111] A. Alfier, M. Beurskens, E. Giovannozzi, M. Kempenaars, H. R. Koslowski, et al., Nucl. Fusion 48, 115006 (2008).

[112] M. Fenstermacher, T. Evans, R. Moyer, G. Porter, J. Boedo, et al., J. Nucl. Mater. 363-365, 476-483 (2007). 
[113] W. Suttrop, T. Eich, J. C. Fuchs, S. Günter, A. Janzer, et al., Phys. Rev. Lett. 106(22), 225004 (2011).

[114] W. Suttrop, A. Herrmann, A. Janzer, M. Maraschek, R. McDermott, et al., First observations of ELM mitigation with new active in-vessel saddle coils in ASDEX Upgrade, in this conference, invited talk, I2.109, submitted to Plasma Phys. Controlled Fusion, 2011.

[115] A. Weller, B. Huber, J. Belapure, M. Sertoli, A. Gude, et al., X-Ray Pulse Height Analysis on ASDEX Upgrade, in this conference, P5.054, 2011.

[116] T. Lunt, Y. Feng, D. Coster, P. de Marn, R. McDermott, et al., EMC3-Eirene simulations of the first Magnetic Perturbation experiments at ASDEX Upgrade, in this conference P4.059, 2011.

[117] G. Matthews, P. Edwards, T. Hirai, M. Kear, A. Lioure, et al., Physica Scripta T128, 137-143 (2007).

[118] G. F. Matthews, P. Edwards, H. Greuner, A. Loving, H. Maier, et al., Physica Scripta T138, 014030 (2009).

[119] C. Ruset, E. Grigore, H. Maier, R. Neu, X. Li, et al., Physica Scripta T128, 171-174 (2007).

[120] T. Hirai, H. Maier, M. Rubel, P. Mertens, R. Neu, et al., Fusion Engineering and Design 82(15-24), 1839 -1845 (2007).

[121] H. Maier, R. Neu, H. Greuner, B. Böswirth, M. Balden, et al., Physica Scripta T138, 014031 (2009).

[122] P. Mertens, presented at the 13th PFMC workshop, I-06, submitted to Physica Scripta (2011).

[123] V. Riccardo, M. Firdaouss, E. Joffrin, G. Matthews, P. Mertens, et al., Physica Scripta 2009(T138), 014033 (2009).

[124] D. Ciric, A. Ash, B. Crowley, I. Day, S. Gee, et al., Fusion Engineering and Design In Press, Corrected Proof, - (2011).

[125] G. Maddison, C. Giroud, G. McCormick, J. Alonso, B. Alper, et al., Nuclear Fusion 51, 042001 (2011).

[126] S. Brezinsek, W. Fundamenski, T. Eich, J. Coad, K. McCormick, et al., Journal of Nuclear Materials In Press, Corrected Proof, - (2010).

[127] T. Loarer, Journal of Nuclear Materials 390-391, 20 - 28 (2009).

[128] S. Jachmich, G. Arnoux, S. Brezinsek, S. Devaux, T. Eich, et al., Journal of Nuclear Materials In Press, Corrected Proof, - (2010).

[129] H. Thomsen, T. Eich, S. Devaux, G. Arnoux, S. Brezinsek, et al., Power Load Characterization for Type-I ELMy H-Modes in JET, in Proc. of the 23rd IAEA Fusion Energy Conference, Daejon, Korea Rep. of, volume IAEA-CN-180, pages EXD/6-6Rb, Vienna, 2010, IAEA.

[130] T. Dittmar, M. Baldwin, R. Doerner, D. Nishijimaa, M. Oberkofler, et al., presented at the 13th PFMC workshop, P12A, submitted to Physica Scripta (2011).

[131] M. Lehnen, A. Alonso, G. Arnoux, N. Baumgarten, S. Bozhenkov, et al., submitted to Nuclear Fusion 51 (2011).

[132] J. Strachan, P. Belo, I. Coffey, G. Corrigan, B. Davis, et al., EDGE2D-EIRENE calculations of NBI shine-through contamination, in this conference, PD2.12, 2011.

[133] K. Krieger, S. Brezinsek, S. Jachmich, S. Lisgo, M. Stamp, et al., Journal of Nuclear Materials 390-391, 110 - 114 (2009).

[134] M. Reinelt, K. Krieger, S. Lisgo, K. Schmid, and S. Brezinsek, Journal of Nuclear Materials In Press, Corrected Proof, - (2010).

[135] M. Reinelt, K. Krieger, and K. Schmidt, presented at the 13th PFMC workshop, P16A, submitted to Physica Scripta (2011).

[136] S. Brezinsek, T. Loarer, K. Krieger, S. Jachmich, M. Tsalas, et al., Nuclear Fusion 51, 073007 (2011).

[137] A. Järvinen, S. Wiesen, M. Groth, K. Krieger, S. Brezinsek, et al., DIVIMP tungsten erosion and transport simulations of an ELM cycle in a JET type-I ELMy H-mode plasma, in this conference, P2.067, 2011.

[138] S. Wiesen, V. Parail, N. Hayashi, G. Corrigan, W. Fundamenski, et al., Integrated modelling of a JET type-I ELMy H-mode pulse and predictions for ITER-Like Wall scenarios, in this conference, invited talk, I3.110, submitted to Plasma Phys. Controlled Fusion, 2011.

[139] A. Herrmann, H. Greuner, N. Jaksic, B. Böswirth, H. Maier, et al., presented at the 13th PFMC workshop, P80A, submitted to Physica Scripta (2011).

[140] G. Luo, presented at the 13th PFMC workshop, I-07, submitted to Physica Scripta (2011).

[141] J. Bucalossi, A. Argouarch, V. Basiuk, O. Baulaigue, P. Bayetti, et al., presented at the 13th PFMC 
workshop, P79B, submitted to Physica Scripta (2011).

[142] G. Sips et al., Scientific preparation for future DT campaigns at JET in support of ITER, in this conference, O5.127, 2011.

[143] A. Pizzuto, F. Gnesotto, M. Lontano, R. Albanese, G. Ambrosino, et al., Nuclear Fusion 50, 095005 (2010).

[144] S. Ishida, P. Barabaschi, and Y. Kamada, Fusion Engineering and Design 85, 2070 - 2079 (2010), Proceedings of the Ninth International Symposium on Fusion Nuclear Technology.

[145] B. Unterberg, R. Jaspers, R. Koch, V. Massaut, J. Rapp, et al., New linear plasma devices for an integrated approach to plasma surface interactions in Fusion Reactors, in 26th Symposium on Fusion Technology, pages P4-096, 2010. 